\title{
Clinical Reasoning: A 65-Year-Old Woman With New Headache, Pulsatile Tinnitus, and Visual Disturbances
}

Laura Donaldson, MD, PhD, Ryan T. Muir, MD, Joanna D. Schaafsma, MD, PhD, and Edward Margolin, MD

Neurology ${ }^{\circledR}$ 2021;97:1039-1044. doi:10.1212/WNL.0000000000012575

\author{
Correspondence \\ Dr. Margolin \\ edmargolin@gmail.com
}

\section{Section 1}

A 65-year-old previously healthy woman noticed new-onset, gradual, blurry vision in her left eye with perceived loss of peripheral vision and pulsatile tinnitus in the left ear for the past 2 weeks. In the past year, she visited 3 different emergency departments for new nonpulsatile and nonthunderclap headaches, which she described as "searing" pain. The headaches were accompanied by nausea without phonophobia or photophobia, were not worsened or triggered by recumbency and Valsalva, and did not wake her from sleep. There were no associated neurologic or systemic symptoms. A noncontrast CT scan of the brain was interpreted as normal. Visual acuity was 20/25 bilaterally. There was no relative afferent pupillary defect. On ophthalmoscopy, she had bilateral severe optic nerve head edema (Figure, A). Formal visual field testing (Humphrey 24-2) showed enlargement of the blind spots in each eye (Figure, B). The remaining neurologic examination was normal.

\section{Questions for Consideration:}

1. What are the red flags in this patient's headache history?

2. What is the differential diagnosis and next most appropriate imaging study to order? 

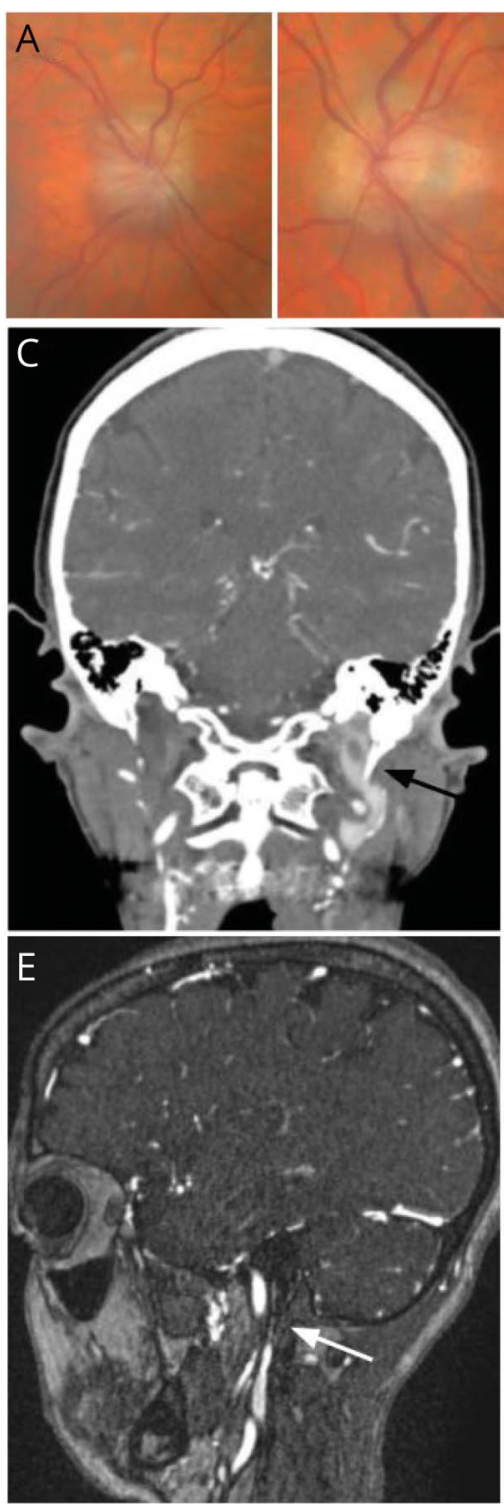
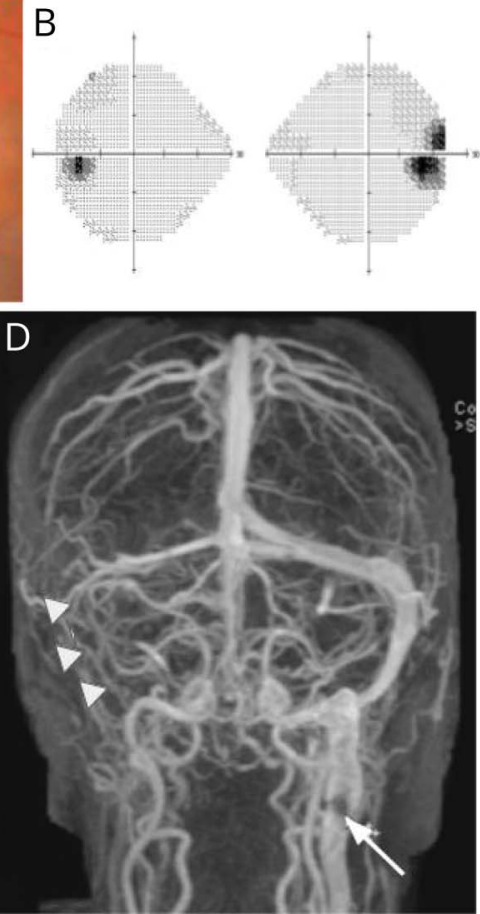

F

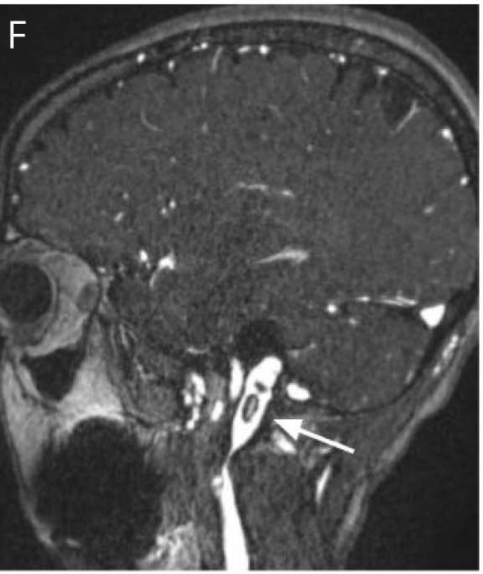

(A) Fundus photographs demonstrating bilateral optic disc edema. (B) Humphrey visual fields (24-2 algorithm) demonstrating blind spot enlargement in the right eye. (C) Coronal contrast-enhanced CT of the head showing compression of the left internal jugular vein by the elongated styloid process (black arrow). (D) MR venography, coronal view demonstrating nonvisualization of the right distal transverse sinus, sigmoid sinus, and internal jugular vein (white arrowheads) with filling defect due to thrombus within the left internal jugular vein (white arrow). (E) Sagittal MR venography image demonstrating the barely visible right internal jugular vein (white arrow). (F) Sagittal MR venography image demonstrating thin, nonocclusive thrombus in the left internal jugular vein (white arrow). MR = magnetic resonance.

\section{GO TO SECTION 2}




\section{Section 2}

This patient's presentation with new headaches at an older age, accompanied by blurred vision and pulse-synchronous tinnitus, raises suspicion for increased intracranial pressure (ICP). Ophthalmoscopy can confirm the presence of ICP by identifying optic disc edema. In addition, even when performed correctly, ophthalmoscopy can be difficult to interpret because common and benign etiologies can mimic optic disc edema, including optic disc drusen and small, crowded, or anomalous optic nerves. ${ }^{1}$

Bilateral optic disc edema with normal visual function in this patient is consistent with papilledema. The differential diagnosis for papilledema is broad, including idiopathic intracranial hypertension (IIH), cerebral venous sinus thrombosis (CVST), hydrocephalus, intracranial spaceoccupying lesions, and meningoencephalitis. Brain parenchymal imaging with MRI or CT including venography should be performed in all patients with suspected papilledema.

Our patient's CT scan revealed an elongated left styloid process, possibly compressing the left internal jugular vein (Figure, C). An elongated styloid process can rarely cause compression of adjacent structures including the carotid artery or jugular vein as it passes between the styloid process and the transverse process of the first cervical vertebrae and can be associated with ischemic events and tinnitus (vascular Eagle syndrome). ${ }^{2}$
Magnetic resonance venography revealed complete opacification of right transverse and sigmoid sinuses with high T2/ FLAIR hyperintense signal within opacified areas without corresponding high signal on T1, consistent with extensive chronic thrombosis. There was also a nonocclusive filling defect in left sigmoid sinus and jugular vein (Figure, D-F). A lumbar puncture to measure the ICP demonstrated an opening pressure of $47 \mathrm{~cm}$ of water with normal CSF composition. No infectious etiology was identified. Her remaining blood work revealed an elevated hemoglobin of $168 \mathrm{~g} / \mathrm{L}$ $(120-160 \mathrm{~g} / \mathrm{L})$ and hematocrit of $0.52(0.38-0.50)$.

Digital subtraction angiography (DSA) was performed to assess the degree of stenosis and pressure gradient across dural venous sinuses, to exclude the presence of dural arteriovenous fistula, and, given her elongated styloid process, to assess the effect of provocative maneuvers (head turning) on venous outflow. DSA demonstrated severe stenosis of left jugular bulb and both right transverse and sigmoid sinuses, resulting in severe venous hypertension. Head turning decreased venous outflow although the area of worst stenosis was located above the level of the styloid process.

Treatment with oral anticoagulation was initiated, and to decrease ICP, acetazolamide was initiated, with close neuroophthalmic follow-up.

\section{Questions for Consideration:}

1. Do you think the elongated styloid process is causative?

2. What additional investigations would you order?

\section{GO TO SECTION 3}




\section{Section 3}

One possible interpretation of our patient's presentation is that jugular vein compression by an elongated styloid process could promote venous stasis, predisposing to thrombosis formation. Although imaging demonstrated an elongated left styloid process, the evidence for it being the culprit for CVST was not definitive on DSA. In addition, thrombosis was more extensive on the right side and the measured styloid length was near the upper limit of normal. Therefore, an alternate diagnosis was pursued.

The recent European guidelines do not recommend screening for occult malignancy or thrombophilia in patients with CVST. ${ }^{3}$
However, given her extensive unprovoked thrombosis and elevated hemoglobin/hematocrit, hypercoagulability screening was performed, including Factor V Leiden, protein $\mathrm{C} / \mathrm{S}$, homocysteine, antiphospholipid and anticardiolipin antibodies, and prothrombin and Janus kinase 2 (JAK2) mutations.

Ultimately, testing for prothrombotic JAK2 V617F mutation was positive.

\section{Questions for Consideration:}

1. Given this result, what further investigations should now be performed?

2. What should the patient be told regarding her future risk of thrombotic events?

GO TO SECTION 4 


\section{Section 4}

The JAK2 V617F substitution is a driver mutation in myeloproliferative neoplasms and is present in nearly all cases of polycythemia vera (PV) and $50 \%-60 \%$ of cases of primary myelofibrosis and essential thrombocytosis. ${ }^{4}$ Our patient had a hemoglobin of $168 \mathrm{~g} / \mathrm{L}$, which had increased from $139 \mathrm{~g} / \mathrm{L} 1$ year earlier. There was also mild thrombocytosis with platelet count 435 (150-400) compared with her previous count of 337. A bone marrow biopsy demonstrated hypercellularity with panmyelosis and atypical cells, which was diagnostic of PV. Treatment with hydroxyurea was recommended but was declined by the patient; thus, serial phlebotomies were used as an alternate treatment strategy.

JAK2 V617F is associated with an increased risk of thrombotic events both in carriers and in patients with myeloproliferative neoplasms, ${ }^{5}$ thus necessitating long-term treatment with direct oral anticoagulation. Over the next year, her papilledema resolved and follow-up venography demonstrated recanalization at the site of previous CVST.

\section{Discussion}

This clinical reasoning case is one of the few reports of CVST arising because of JAK2 V617F mutation - an underappreciated etiology and diagnostic consideration of CVST. Testing for JAK2 mutation must be performed in all CVST patients with elevated hemoglobin and should be considered even in those with normal CBC. ${ }^{6}$

Although well-appearing patients with papilledema are often presumed to have $\mathrm{IIH}$, it is a diagnosis of exclusion and requires normal neuroimaging with venography (excluding indirect signs of raised ICP), normal CSF analysis, and no neurologic deficits beyond a sixth nerve palsy. ${ }^{7}$ This patient was not in the typical demographic group for IIH because only approximately $5 \%$ of patients are older than 50 years at diagnosis. ${ }^{8}$ Venography should be performed in all patients with papilledema who are not in a typical group for IIH (and some would argue it should be performed in all) because CVST is a relatively common secondary cause of raised ICP.?

Venous stasis, vessel wall injury, and hypercoagulability (Virchow triad) are responsible for development of venous thrombosis. Although CVST is not commonly seen in Eagle syndrome, it has been reported in some with styloid-jugular compression with high pressure gradients across the region of venous compression with resolution poststyloidectomy. ${ }^{8,10,11}$ Styloidectomy was considered in this case; however, when the $J A K 2$ mutation and bone marrow biopsy confirmed PV, noninvasive treatment with anticoagulation and serial phlebotomies commenced. Although it is unclear whether the elongated styloid process contributed to CVST in our patient, we hypothesize that the combination of her underlying hypercoagulable state and venous stasis produced by an elongated styloid process together increased her risk of developing CVST.
The pathophysiology of hypercoagulable states in patients with JAK2 V617F mutation is multifactorial. In patients with overt myeloproliferative neoplasms, hyperviscosity is a probable contributor. However, the mutation alone carries an increased risk of thrombosis. ${ }^{5}$ One additional mechanism for thrombus formation is abnormal neutrophil activation leading to altered cell adhesion and binding of platelets and leukocytes to vascular endothelium. ${ }^{12}$

The evidence regarding optimal duration of anticoagulation after the initial treatment of CVST with low-molecularweight heparin is not clear, and the general recommendation is between 3 and 12 months. ${ }^{3}$ In patients with PV, the risk of recurrent thrombosis must be managed and cytoreductive therapy such as hydroxyurea is recommended in older patients with PV or in those with a previous thrombotic event. ${ }^{13}$ Because our patient declined hydroxyurea, phlebotomy and long-term anticoagulation with apixaban were chosen. Although comparative safety and efficacy of direct oral anticoagulants (DOACs) vs warfarin have not yet been established in randomized control trials for patients with chronic CVST, emerging evidence suggests that both are effective in preventing recurrence. ${ }^{14}$ DOACs are increasingly used because of their convenience and favorable pharmacologic properties.

This clinical reasoning case is unique because it highlights an underappreciated diagnostic etiology of CVST: JAK2 mutation. We underline unique clinical characteristics of patients with JAK2 mutation and describe the clinical reasoning that led to a correct diagnosis and management of the disease in our patient. Recognition of optic disc edema was paramount in this case, highlighting the importance of ophthalmoscopy in evaluating patients with headaches and underpinning the importance of collaborative relationships between neurologists and neuro-ophthalmologists. There was some degree of unilateral jugular vein compression by an elongated styloid process that may have contributed to an upstream vulnerable milieux of cerebral venous stasis. While this was a tempting initial explanation for thrombosis, a hypercoagulable workup revealed that a prothrombotic mutation in JAK2 was the most likely underlying cause of CVST.

\section{Study Funding}

The authors report no targeted funding.

\section{Disclosure}

None of the authors have relevant disclosers to submit. Go to Neurology.org/ $\mathrm{N}$ for full disclosures.

\section{Appendix Authors}

\begin{tabular}{lll}
\hline Name & Location & Contribution \\
\hline Laura & Department of Ophthalmology & Wrote the article \\
$\begin{array}{l}\text { Donaldson, } \\
\text { MD, PhD }\end{array}$ & $\begin{array}{l}\text { and Vision Science, University of } \\
\text { Toronto }\end{array}$ & \\
\hline
\end{tabular}

Continued 
Appendix (continued)

\begin{tabular}{lll}
\hline Name & Location & Contribution \\
\hline $\begin{array}{l}\text { Ryan T. Muir, } \\
\text { MD }\end{array}$ & $\begin{array}{l}\text { Department of Medicine, Division } \\
\text { of Neurology, University of } \\
\text { Toronto }\end{array}$ & $\begin{array}{l}\text { Revised the article for } \\
\text { intellectual } \\
\text { contribution }\end{array}$ \\
\hline $\begin{array}{l}\text { Joanna D } \\
\text { Mchaafsma, } \\
\text { MD, PhD }\end{array}$ & $\begin{array}{l}\text { Department of Medicine, Division } \\
\text { of Neurology, University of }\end{array}$ & $\begin{array}{l}\text { Revised the article for } \\
\text { intellectual } \\
\text { contribution }\end{array}$ \\
\hline $\begin{array}{l}\text { Edward } \\
\text { Margolin, MD }\end{array}$ & $\begin{array}{l}\text { Department of Ophthalmology } \\
\text { and Vision Science, and } \\
\text { Department of Neurology, } \\
\text { University of Toronto }\end{array}$ & Wrote the article \\
\hline
\end{tabular}

\section{References}

1. Donaldson L, Margolin E. Approach to patient with unilateral optic disc edema and normal visual function. J Neurol Sci. 2021;424:117414.

2. Zamboni P, Scerrati A, Menegatti E, et al. The eagle jugular syndrome. BMC Neurol. 2019;19(1):333.

3. Ferro JM, Bousser MG, Canhão P, et al. European Stroke Organization. European Stroke Organization guideline for the diagnosis and treatment of cerebral venous thrombosis - endorsed by the European Academy of Neurology. Eur J Neurol. 2017; 24(10):1203-1213.
4. Loscocco GG, Guglielmelli P, Vannucchi AM. Impact of mutational profile on the management of myeloproliferative neoplasms: a short review of the emerging data. Onco Targets Ther. 2020;13:12367-12382.

5. Shetty S, Kulkarni B, Pai N, Mukundan P, Kasatkar P, Ghosh K. JAK2 mutations across a spectrum of venous thrombosis cases. Am J Clin Pathol. 2010;134(1):82-85

6. Lamy M, Palazzo P, Agius P, et al. Should we screen for janus kinase 2 V617F mutation in cerebral venous thrombosis?. Cerebrovasc Dis. 2017;44(3-4):97-104.

7. Friedman DI, Liu GT, Digre KB. Revised diagnostic criteria for the pseudotumor cerebri syndrome in adults and children. Neurology. 2013;81(13):1159-1165.

8. Bruce BB, Kedar S, Van Stavern GP, Corbett JJ, Newman NJ, Biousse V. Atypical idiopathic intracranial hypertension: normal BMI and older patients. Neurology. 2010; 74(22):1827-1832.

9. Kisilevsky E, Yu E, Margolin E. Papilledema and extensive dural sinus thrombosis due to JAK2 mutation. J Neuroophthalmol. 2021;41(3):e307-e308.

10. Zhang FL, Zhou HW, Guo ZN, Yang Y. Eagle syndrome as a cause of cerebral venous sinus thrombosis. Can J Neurol Sci. 2019;46(3):344-345.

11. Dashti SR, Nakaji P, Hu YC, et al. Styloidogenic jugular venous compression syndrome: diagnosis and treatment: case report. Neurosurgery. 2012;70(3):E795-E799.

12. Ball S, Thein KZ, Maiti A, Nugent K. Thrombosis in the Philadelphia negative classical myeloproliferative neoplasms: a narrative review on epidemiology, risk-assessment, and pathophysiologic mechanism. J Thromb Thrombolysis. 2018;45:516-528.

13. Barbui T, Tefferi A, Vannucchi AM, et al. Philadelphia chromosome-negative classical myeloproliferative neoplasms: revised management recommendations from European LeukemiaNet. Leukemia. 2018;32(5):1057-1069.

14. Ferro JM, Coutinho JM, Dentali F, et al; RE-SPECT CVT Study Group. Safety and efficacy of dabigatran etexilate vs dose-adjusted Warfarin in patients with cerebral venous thrombosis: a randomized clinical trial. JAMA Neurol. 2019;76(12): $1457-1465$.

\section{Manage Your Career $\mid$ Recruit Top Talent}

The AAN's Neurology Career Center is the largest job site specifically for neurologists. Visit careers.aan.com to find your next hire or search from hundreds of open positions in neurology.

\section{Sign Up for the AAN's Axon Registry}

The AAN encourages its US members to show their interest in participating in the Axon Registry ${ }^{\circledR}$ by signing up today.

Use the Axon Registry to:

- Simplify reporting requirements under MACRA's Quality Payment Program and avoid penalties while reducing your administrative burden

- Meet your MOC Part IV requirements and waive up to eight credits of Part II Self-Assessment

- Choose from 22 AAN neurology-specific quality measures that fit your practice

- Use data to understand your practice and identify where improvements can be made to patient care

- Manage your patients at a population level; look at a specific group of patients based on conditions, risk factors, demographics or outcome

- Demonstrate your value to payers when negotiating reimbursement

- Enjoy multi-year, fee-free access when you sign the agreements and integrate your EHR with the registry

Learn more at AAN.com/view/Axon and send your questions to registry@aan.com. 


\section{Neurology}

\section{Clinical Reasoning: A 65-Year-Old Woman With New Headache, Pulsatile Tinnitus, and Visual Disturbances}

Laura Donaldson, Ryan T. Muir, Joanna D. Schaafsma, et al.

Neurology 2021;97;1039-1044 Published Online before print July 29, 2021

DOI 10.1212/WNL.0000000000012575

This information is current as of July 29, 2021

\section{Updated Information \& Services}

References

Subspecialty Collections

Permissions \& Licensing

Reprints including high resolution figures, can be found at: http://n.neurology.org/content/97/22/1039.full

This article cites 14 articles, 2 of which you can access for free at: http://n.neurology.org/content/97/22/1039.full\#ref-list-1

This article, along with others on similar topics, appears in the following collection(s):

Cerebral venous thrombosis

http://n.neurology.org/cgi/collection/cerebral_venous_thrombosis Clinical neurology examination

http://n.neurology.org/cgi/collection/clinical_neurology_examination Optic nerve

http://n.neurology.org/cgi/collection/optic_nerve

Secondary headache disorders

http://n.neurology.org/cgi/collection/secondary_headache_disorders

Visual fields

http://n.neurology.org/cgi/collection/visual_fields

Information about reproducing this article in parts (figures,tables) or in its entirety can be found online at:

http://www.neurology.org/about/about_the_journal\#permissions

Information about ordering reprints can be found online:

http://n.neurology.org/subscribers/advertise

Neurology ${ }^{\circledR}$ is the official journal of the American Academy of Neurology. Published continuously since 1951, it is now a weekly with 48 issues per year. Copyright (O) 2021 American Academy of Neurology. All rights reserved. Print ISSN: 0028-3878. Online ISSN: 1526-632X.

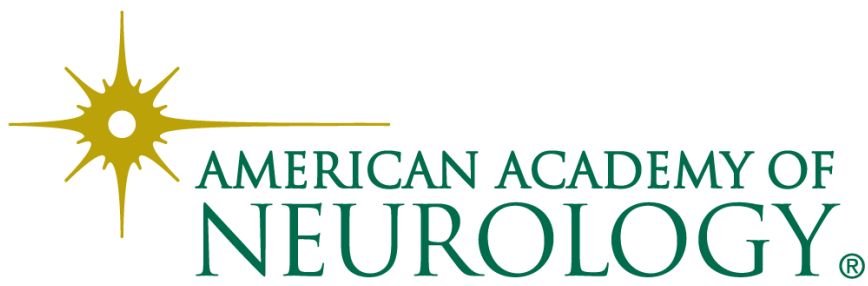

